\title{
CTP-Based Tissue Outcome: Promising Tool to Prove the Beneficial Effect of Mechanical Recanalization in Acute Ischemic Stroke
}

\section{CTP basiertes Gewebe-Outcome als Erfolgsparameter der mechanischen Rekanalisation bei akutem ischämischen Schlaganfall}

Authors
Affiliations
Key words
ischemia/infarction
acute
interventional procedures
brain
arteries
obstruction/occlusion

received $\quad 16.9 .2014$

accepted $\quad 8.1 .2015$

\section{Bibliography}

DOI http://dx.doi.org/

10.1055/s-0034-1399189

Published online: 28.4 .2015

Fortschr Röntgenstr 2015; 187 :

459-466 @ Georg Thieme

Verlag KG Stuttgart · New York

ISSN 1438-9029

\section{Correspondence}

Franziska Drewer-Gutland

Department of Clinical

Radiology, University Hospital Muenster

Albert-Schweitzer-Campus 1

Gebäude A1

48149 Muenster

Germany

Tel.: ++ 49/0251/8347301

Fax: ++49/0251/8349656

Franziska.Drewer-Gutland@

uni-muenster.de

F. Drewer-Gutland ${ }^{1}$, A. Kemmling ${ }^{2}$, S. Ligges ${ }^{3}$, M. Ritter ${ }^{4}$, R. Dziewas ${ }^{4}$, E. B. Ringelstein ${ }^{4}$, T. U. Niederstadt ${ }^{1}$, W. Heindel ${ }^{1}$, V. Heßelmann ${ }^{5}$

Affiliation addresses are listed at the end of the article.

\section{Zusammenfassung \\ $\nabla$}

Hintergrund: Zur Überprüfung des gewebsprotektiven Effekts der mechanischen Rekanalisation, untersuchten wir das CTP-basierende Gewebe Outcome („GO“) und korrelierten diesen Parameter mit dem 3-Monats klinischen Outcome („KO“).

Material und Methoden: 159 Patienten mit zerebralen Gefäßverschlüssen wurden mittels CCT, CT-Angiografie (CTA) und CT-Perfusion (CTP) untersucht und anschließend mechanisch rekanalisiert. Für das finale Infarktvolumen wurde ein natives CCT nach 24 Std. angefertigt. Das „GO“ ( „Prozentualer Mismatch Loss“ = \%ML) wurde als Differenz zwischen initialer Penumbra des CTP und finalem Infarktvolumen im Kontroll-CCT definiert. Das 3-Monats „modified-Rankin-Scale“ (mRS), Alter, Auftreten von Blutungen, Rekanalisationszeit, TICI-Score, Kollateralstatus, Infarktzunahme und finales Infarktvolumen wurden bestimmt. Mithilfe des Spearman's Korrelationskoeffizienten und der nominalen Regressionsanalyse überprüften wir den Einfluss dieser Parameter auf das mRS.

Ergebnisse: Signifikante Korrelationen mit dem mRS bestehen für die Parameter \%ML ( $c=0,48$, $\mathrm{p}<0,001)$, finales Infarktvolumen $(\mathrm{c}=0,52$, $\mathrm{p}<0,001)$, TICI score $(\mathrm{c}=-0,35, \mathrm{p}<0,001)$, initialer Infarktkern $(c=0,14, p=0,039)$ und Alter $(c=0,37, p<0,001)$. In der Regressionsanalyse konnte \%ML die mRS-Klassifikation zu 38,5\% korrekt vorhersagen; die Subklassen mRS 1 oder 6 konnten zu 86,4\% bzw. 60,9\% vorhergesagt werden. Es konnten keine Korrelationen mit mRS für die Parameter Rekanalisationszeit, Kollateralstatus und Auftreten von Blutungen festgestellt werden.

Schlussfolgerung: Das CT-basierte GO beschreibt besser als der TICI-Score den klinischen Erfolg der mechanischen Rekanalisation, so dass nicht die Re-

\section{Abstract \\ $\nabla$}

Purpose: To prove the tissue-protecting effect of mechanical recanalization, we assessed the CT perfusion-based tissue outcome ("TO") and correlated this imaging parameter with the 3-month clinical outcome ("CO").

Materials and Methods: 159 patients with large intracranial artery occlusions revealing mechanical recanalization were investigated by $\mathrm{CCT}, \mathrm{CT}$ angiography (CTA) and CT perfusion (CTP) upon admission. For the final infarct volume, native CCT was repeated after $24 \mathrm{~h}$. The "TO" ("percentage mismatch loss" =\%ML) was defined as the difference between initial penumbral tissue on CTP and final infarct volume on follow-up CCT. We monitored the three-month modified Rankin Scale (mRS), age, bleeding occurrence, time to recanalization, TICI score and collateralization grade, infarct growth and final infarct volume. Spearman's correlation and nominal regression analysis were used to evaluate the impact of these parameters on mRS.

Results: Significant correlations were found for \% ML and mRS ( $c=0.48, p<0.001)$, for final infarct volume and $\mathrm{mRS}(\mathrm{c}=0.52, \mathrm{p}<0.001)$, for $\mathrm{TICl}$ score and $\mathrm{mRS}(\mathrm{c}=-0.35, \mathrm{p}<0.001)$, for initial infarct core and mRS ( $c=0.14, p=0.039)$ as well as for age and mRS ( $c=0.37, p<0.001)$. According to the regression analysis, \%ML predicted the classification of mRS correctly in $38.5 \%$ of cases. The subclasses mRS 1 and 6 could be predicted by \% ML with $86.4 \%$ and $60.9 \%$ reliability, respectively. No correlations were found for time to recanalization and $\mathrm{mRS}$, for collateralization grade and $\mathrm{mRS}$, and for post-interventional bleeding and mRS.

Conclusion: Better than the TICI score, CT-based TO predicts the clinical success of mechanical recanalization, showing that not recanalization, but reperfusion should be regarded as a surrogate parameter for stroke therapy. 
kanalisation selbst, sondern die Reperfusion den geeigneten Kontrollparameter darstellt.

Kernaussagen:

- \%ML und finales Infarktvolumen sind direkte Kontrollparameter für eine erfolgreiche mechanische Rekanalisation.

- Das klinische Outcome nach mechanischer Rekanalisation wird durch \%ML zuverlässig vorhergesagt, welches den Nutzen der interventionellen Therapie zerebraler Gefäßverschlüsse widerspiegelt.

- Anstelle der Rekanalisation sollte die Gewebsreperfusion den geeigneten Kontrollparameter einer erfolgreichen interventionellen Schlaganfallstherapie darstellen.
Key Points:

\% \%L as well as the final infarct volume can make a direct point about the immediate effect of successful mechanical recanalization.

- The clinical outcomes after mechanical recanalization are reliably predicted by \%ML, reflecting the benefit of escalation therapy including interventional reopening of parent vessel occlusions.

- Not recanalization but rather reperfusion should be regarded as a surrogate parameter for successful stroke therapy.

Citation Format:

- Drewer-Gutland F, Kemmling A, Ligges S et al. CTP-Based Tissue Outcome: Promising Tool to Prove the Beneficial Effect of Mechanical Recanalization in Acute Ischemic Stroke. Fortschr Röntgenstr 2015; 187: 459-466

(mRS) by regression analysis to define the most predictive parameters for interventional treatment.

Stroke is the leading cause of acquired disability and mortality in adults worldwide [1]. In the RECOST study on mechanical thrombectomy, the site of the occluded artery (internal carotid artery (ICA), medial cerebral artery (MCA) or basilar artery (BA)), hyperglycemia and initial NIHSS score were identified as prognostic factors for clinical outcome ("CO"), but no correlation with time to recanalization was observed [2]. No influence on "CO" was found for the time interval between symptom onset and time of recanalization, but was noted for grade of recanalization, extent of the initial mismatch volume, and duration of interventional procedure [3].

A recent randomized trial did not identify a favorable effect of a penumbral pattern for "CO" in patients undergoing endovascular therapy [4]. The Defuse trail, however, showed that a mismatch in initial MRI is associated with a more favorable "CO" [5]. In a recent investigation of collateral status and "CO" a significant link was found between these two parameters, so that good collateral status and penumbral tissue may support successful reperfusion [6].

In addition to intravenous (i.v.) lysis, mechanical devices play an increasing role in endovascular stroke therapy [7]. Current nonrandomized studies describe a superiority of mechanical recanalization over i. v. lysis with a reduced mortality of $50-75 \%$. Likewise, a favorable mRS of $0-2$ was found in $70 \%$ of patients with MCA occlusions [2,8].

However, the IMS III trial failed to prove any benefit of mechanical recanalization in a three-month "CO" when compared to i.v. lysis. The authors critically stated that one of the retriever systems used was outdated [9]. However, even recent studies using stent retrievers could not find a significant difference in functional independence with add-on endovascular therapy applied after i. v. t-PA. Thus, the superiority of mechanical recanalization still remains uncertain [9-11] and further studies are needed to validate this correlation $[7,12,13]$.

Moreover, we want to address the impact of recanalization on TICI score and tissue outcome ("TO"), considering percentage mismatch loss (\%ML), infarct core and final infarct volume on three-month "CO" (mRS). We believe that the post-interventional "TO", as calculated by \%ML on the basis of CT perfusion and control CCT, is more accurate in investigating the efficiency of mechanical recanalization in comparison to TICI score alone. We want to investigate the predictive value of \%ML, age, time to recanalization, bleeding and collateralization grade in terms of "CO"

\section{Materials and Methods}

$\nabla$

From 04/2010 through 08/2012, research was carried out on patients with acute large artery occlusive stroke at the Department of Clinical Radiology of the University Hospital Muenster. The database for our study included 159 patients: 66 women and 93 men, aged 18 - 92 years (mean: 65.6 years). 91 presented with MCA, 30 with BA and 38 with carotid-T occlusions. Mechanical thrombectomy was applied to 151 patients. Penumbra systems were used in 97, pRESET clot retrievers in 48, and $3 \mathrm{D}$ devices (penumbra) in 6 of our cases. Statistically complete datasets could be achieved for 109 patients with minor missing information in two datasets so that regression analysis partly considered 107 datasets ( $\bullet$ Table 2 ). According to the "guidelines for adults with ischemic stroke", patients were included according to the following criteria: (1) stroke onset within less than six hours $(<6 \mathrm{~h})$ between symptom onset and beginning of interventional treatment, (2) an infarct volume of less than one-third of the MCA territory, (3) CTA-proven proximal cerebral artery occlusion, including M1-MCA, BA and carotid-T, (4) persisting occlusion during the diagnostic part of the DSA [14].

\section{Diagnostic Imaging}

Patients were examined by comprehensive multimodal CT, comprising native $\mathrm{CT}, \mathrm{CT}$ angiography (CTA) and whole-brain CT perfusion (CTP) performed with our dual source CT equipment (Siemens Definition Flash, Siemens AG, Erlangen, Germany).

Non-contrast-enhanced CT (NECT) was used for infarct and bleeding detection. Patients with hemorrhagic strokes were excluded $[15,16]$. NECT was performed using a routine protocol $(120 \mathrm{kV}, 320 \mathrm{mAs}$, collimation $2 \times 20 \times 0.6 \mathrm{~mm})$. Images were reconstructed with a slice thickness of $5.0 \mathrm{~mm}$ with no overlap using a medium sharp convolution kernel (H30f).

\section{CT angiography}

A CT angiogram from the aortic arch to the apex of the skull was obtained after injection of $80 \mathrm{ml}$ of contrast medium at a flow rate of $4 \mathrm{ml} / \mathrm{s}$. CT scan parameters were: $100 \mathrm{kV}$, care dose $4 \mathrm{~d}$, collimation $2 \times 64 \times 0.6 \mathrm{~mm}$. Images were reconstructed with a slice thickness of $1.0 \mathrm{~mm}$ and an increment of $0.7 \mathrm{~mm}$ using a soft convolution kernel (H20 s). 
Table 1 Correlation of following parameters (see below) with mRS (modified Rankin-Scale) in all cases and in vascular territories considered separately (ICA, MCA and BA). Table 1 shows all relevant correlations for parameters being observed in this study with mRS (modified Rankin-Scale) as the clinical follow-up parameter: \%ML, infarct core, final infarct, $\mathrm{TICI}$, age, time to recanalization and grade of collaterization. Those correlations were implemented for all cases and for vascular territories separately (ICA, MCA and BA) on the basis of Spearman-Rho. The level of significance was set to ${ }^{*} p<0.05$, and high significance levels were set to ${ }^{* *} p<0.001$. Please note the high correlation for parameters \%ML and final infarct.

Tab. 1 Korrelation von folgenden Parametern (siehe unten) mit mRS (modified Rankin Scale) für alle Fälle und für die einzelnen Gefäßterritorien (ICA, MCA und BA). Tab. 1 zeigt alle relevanten Korrelationen für die Parameter, die in der Studie beobachtet wurden, mit dem klinischen Kontrollparameter mRS (modified Rankin Scale): \%ML, Infarktkern, finaler Infarkt, TICI, Alter, Rekanalisationszeit und Kollateralisationgrad. Diese Korrelationen wurden sowohl für alle Fälle, als auch für die einzelnen Gefäßterritorien (ICA, MCA und BA) auf Basis des Spearman-Rho's durchgeführt. Das Signifikanzniveau wurde auf ${ }^{*} p<0,05$ und das Hoch-Signifikanzniveau auf ${ }^{* *} p<0,001$ festgelegt. Bitte achten Sie auf die hohe Korrelation für die Parameter \%ML und finaler Infarkt.

\begin{tabular}{|lllll|}
\hline parameter & whole group & ICA & MCA & BA \\
\hline infarct core & $0.14^{*}$ & $0.44^{*}$ & 0.06 & $0.47^{*}$ \\
\hline final infarct & $0.52^{* *}$ & $0.62^{* *}$ & $0.48^{* *}$ & $0.78^{* *}$ \\
\hline \%ML & $0.48^{* *}$ & $0.46^{*}$ & $0.49^{* *}$ & $0.47^{*}$ \\
\hline $\mathrm{TICl}$ & $-0.35^{* *}$ & $-0.42^{*}$ & $-0.52^{* *}$ & -0.02 \\
\hline Age & $0.37^{* *}$ & $0.43^{*}$ & $0.33^{*}$ & 0.30 \\
\hline time to rec. & 0.07 & 0.08 & 0.01 & 0.27 \\
bleeding & 0.02 & 0.07 & 0.02 & 0.06 \\
\hline collateralization & 0.02 & 0.08 & 0.05 & 0.10 \\
\hline
\end{tabular}

Correlation coefficient: Spearman-Rho, level of significance ${ }^{*} \mathrm{p}<0.05,{ }^{* *} \mathrm{p}<0.001$. Korrelationskoeffizient: Spearman-Rho, Signifikanzniveau ${ }^{*} p<0,05,{ }^{* *} p<0,001$.

\section{CT perfusion}

For CT perfusion the skull was scanned repeatedly after the injection of $30 \mathrm{ml}$ of contrast medium with a flow of $4 \mathrm{ml} / \mathrm{s}$ with the following parameters: $80 \mathrm{kV}, 200 \mathrm{mAs}$, collimation $2 \times 64 \times 0.6 \mathrm{~mm}$, allowing acceptable image quality using reduced tube current and voltage with respect to the standard protocol. The protocol was used for all patients including those younger than 50 if major stroke was suspected. A range of $90 \mathrm{~mm}$ from the skull base to the top of the calvarium was covered with a temporal increment of $1.5 \mathrm{~s}$ over a period of $50 \mathrm{~s}$, which is regarded as the acceptable compromise between temporal resolution and radiation dose [17]. Perfusion datasets were reconstructed with a slice thickness of $10.0 \mathrm{~mm}$ using a soft convolution kernel (H20 s). Simultaneously, CCT, rCBV and MTT maps were generated for further analysis.

A follow-up CCT was performed after 24 hours (+/-8 hours) in order to evaluate the final infarct volume.

Tissue Outcome "TO" (measure: \%-mismatch loss "\%ML") The perfusion data was calculated using the VPCT program (Siemens Medical Solutions, Forchheim, Germany). CTP parameter maps ( $\mathrm{rCBV}$, rCBF and MTT) were calculated based on least square deconvolution using a mean arterial input function measured in early arterial voxels selected automatically with supervision.

rCBV and MTT maps and the post-interventional CCT were imported into the ANALYZE evaluation software for semiautomated slice-by-slice segmentation and measurement of the penumbral infarction volume [18]. The segmentation under visual assessment was made by one reader with manual adjustment of win-
Table 2 Predictive classification of $\mathrm{mRS}(0,1,2,3,4,5,6)$ by all parameters (\% ML, age, occurrence of bleeding) and by \%ML itself according to nominal regression models. "Due to minor relevant missing single values in two datasets, the total number of datasets in regression analysis 'all parameters' is 107 instead of 109." Table 2 shows the percentage predictability of mRS in clinical follow-up by all relevant parameters (\%ML, bleeding and age) and \%ML on its own according to two different fitted nominal regression models. Note the very high percentage predictability of $86.4 \%$ in $\mathrm{mRS}$ subgroup 1 , presenting the fact that complete reopening of the vessel without tissue loss might result in almost complete recovery from stroke.

Tab. 2 Vorhersage der Klassifizierung von $\operatorname{mRS}(0,1,2,3,4,5,6)$ durch alle Parameter (\%ML, Alter, Auftreten von Blutungen) und durch \%ML alleine anhand einer nominalen Regressionsanalyse. „Aufgrund von weniger relevanten fehlenden Einzelwerten in zwei Datensätzen, ist die Gesamtsumme der Datensätzen in der Regressionsanalyse, all parameters ' 107 anstelle von 109." Tab. 2 zeigt die prozentuale Vorhersagbarkeit von mRS im klinischen Verlauf durch alle relevanten Parameter (\%ML, Blutung und Alter) und durch \% $\mathrm{ML}$ alleine anhand 2 verschiedener nominaler Regressionsanalysen. Achten Sie auf die hohe prozentuale Vorhersagbarkeit der mRS Subgruppe $1 \mathrm{mit}$ $86,4 \%$. Dieses zeigt, dass eine komplette Gefäßeröffnung ohne nachfolgenden Gewebsverlust eine komplette Erholung von schlaganfallstypischen Symptomen bedeuten könnte.

\begin{tabular}{|c|c|c|}
\hline $\begin{array}{l}\text { classification } \\
\text { (mRS) }\end{array}$ & $\begin{array}{l}\text { all parameters } \\
\text { correctly predicted (\%) }\end{array}$ & $\begin{array}{l}\text { \%ML separately } \\
\text { correctly predicted (\%) }\end{array}$ \\
\hline 1 & $15 / 22(68.2)$ & $19 / 22(86.4)$ \\
\hline 2 & $6 / 18(33.3)$ & $2 / 19(10.5)$ \\
\hline 3 & $2 / 15(13.3)$ & $0 / 15(0)$ \\
\hline 4 & $12 / 20(60.0)$ & $7 / 21(33.3)$ \\
\hline 5 & $0 / 9(0)$ & $0 / 9(0)$ \\
\hline 6 & $18 / 23(78.3)$ & $14 / 23(60.9)$ \\
\hline total & $53 / 107(49.5)$ & $42 / 109(38.5)$ \\
\hline
\end{tabular}

dow width for optimal contrast. All cases were validated by an experienced second reader to optimize the segmentation process (० Fig. 1).

Infarct core was operationally defined by visual perfusion deficit in $\mathrm{rCBV}$ parameter maps below $2.0 \mathrm{ml} / 100 \mathrm{ml}$ ( $\bullet$ Fig. 1a).

Tissue at risk of infarction in case of failed recanalization was operationally defined by visual perfusion deficit in MTT parameter maps of at least $7 \mathrm{~s}$ [18] ( $\bullet$ Fig. 1b).

The volumetric difference between tissue at risk of infarction in case of failed recanalization and infarct core was defined as the penumbra (rCBV and MTT mismatch ( $\bullet$ Fig. 1e)). The percentage of penumbra that infarcts after recanalization was defined as the percentage of mismatch loss (\%ML), which is equivalent to the volume of infarct growth ( $\bullet$ Fig. 1f) $(=$ rCBV lesion ( $\bullet$ Fig. 1 d) subtracted from the final infarct ( $\bullet$ Fig. 1c) per total volume of penumbra.)

The following formula was used for estimation of the percentage of mismatch loss:

$\% \mathrm{ML}=100 \times$ (follow-up CCT volume - initial rCBV volume)/(initial MTT volume - initial rCBV volume) [19].

\section{Collateralization}

A 3 -grade score $(1=$ high, $2=$ middle, $3=$ low $)$ as defined by Knauth et al. [20, 21] and further refined by CTA post-processing techniques [22] was used as a reference for the evaluation of collaterals. The scale was defined as: (1) contrast filling being visible from pial collaterals to the M1 segment in CTA and DSA, (2) contrast filling being visible from the periphery to M2 branches in CTA and DSA, (3) only peripheral vascular structures show contrast filling. 


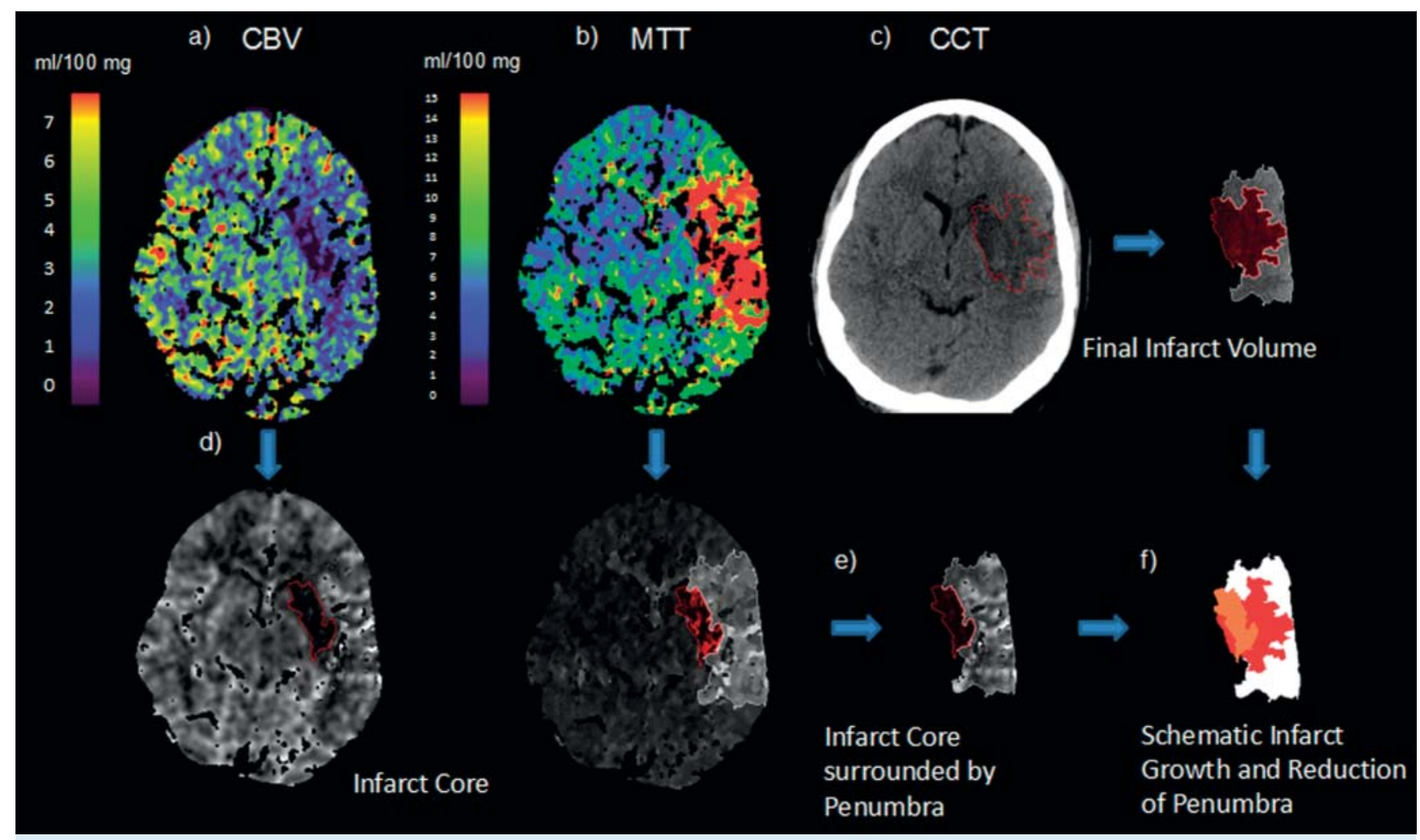

Fig. 1 shows a initial CBV color map, b initial MTT color map, c CCT with final infarct volume, $\mathbf{d}$ CBV presenting the infarct core, e MTT presenting the penumbra, $\mathbf{f}$ a schematic survey of infarct growth (red-colored) and as a consequence thereof reduction of penumbra (white-colored). Note the white part (penumbra), which can be interpreted as salvaged after mechanical recanalization therapy.
Abb. 1 zeigt a die initiale CBV Farbtabelle, $\mathbf{b}$ die initiale MTT Farbtabelle, c das Kontroll-CCT mit finalem Infarktvolumen, $\mathbf{d}$ das CBV mit Infarktkern, e das MTT mit Penumbra, f eine schematische Darstellung des Infarktzuwachses (rot) und als Konsequenz hieraus die Reduktion der Penumbra (weiß). Achten Sie auf den weißen Bereich (Penumbra), der nach mechanischer Rekanalisation als gerettet angesehen werden kann.

\section{DSA}

Anesthesia was performed in the angiography suite using a standardized protocol with a time frame of less than $60 \mathrm{~min}$ between CTA and the start of angiography. DSA was performed using a biplane angiography system (Philips, Allura, FD 2020). Post-interventionally, the success of mechanical recanalization was estimated using the TICI score [23].

\section{Medication}

rtPA was applied as the initial bolus of $10 \mathrm{mg}$ and then continuously with $10 \mathrm{mg} / \mathrm{h}$ i.v. ("bridging dose"). After local i.a. catheter placement, rtPA was given directly into the guiding catheter with a flow velocity of $40 \mathrm{mg} / \mathrm{h}$ and to a maximum dose of $0.9 \mathrm{mg} / \mathrm{kg}$ body weight. rtPA application was stopped after recanalization. The total applied i.a. rtPA dose ranged from $20 \mathrm{mg}$ to $80 \mathrm{mg}$. By 24 hours (h) after the intervention, heparin was given at a dose of $15000 \mathrm{IE} / 24 \mathrm{~h}$.

\section{Clinical outcome "CO" (measure: modified Rankin Scale "mRS")}

At 3 months after the intervention, patients were contacted to score the modified Rankin Scale (mRS). A good outcome was defined as an mRS of $0-2$ and a poor outcome was represented by a mRS of $3-6$.

\section{Results}

$\nabla$

Statistically acceptable data findings considering \%ML and mRS were obtained for (107) 109 of the initial 159 patients, because 36 did not receive the full CCT examination needed for the calculation of mismatch, and a further 14 could not be contacted due to the possibility of having moved to a nursing home or another facility. In two patient datas minor errors were detected by statistical evaluation process but did not lead to complete exclusion of the datasets from the evaluation.

During angiography, a good collateralization grade was seen in $64 / 155$ patients (41.3\%), a medium grade was found in $40 / 155$ patients (25.8\%), and 51/155 patients (32.9\%) showed the lowest collateralization grade.

Regarding the TICI score, 79/158 patients presented with a high TICI grade ( 3 and $2 b$ ), 39/158 with a medium grade (2a and 2 ), and $16 / 158$ with a low TICI grade (1). In 24/158 cases, mechanical recanalization was not feasible (TICI 0 ) due to missing access to tortuous supraaortal vessels $(n=14)$ and reocclusion or failure of reopening the artery $(n=10)$, mostly occurring due to the usage of more old fashioned devices. The overall recanalization rate reached $74.6 \%$.

The mean time to recanalization was $4: 06 \mathrm{~h}$. The mean duration of intervention was $2: 30 \mathrm{~h}$. For the penumbra device $2: 32 \mathrm{~h}$ and for the pRESET clot retriever 38 minutes were measured. Clinically relevant bleeding, which requires control imaging, was found in $20(12.6 \%)$ patients. In penumbra cases twice as high bleeding 

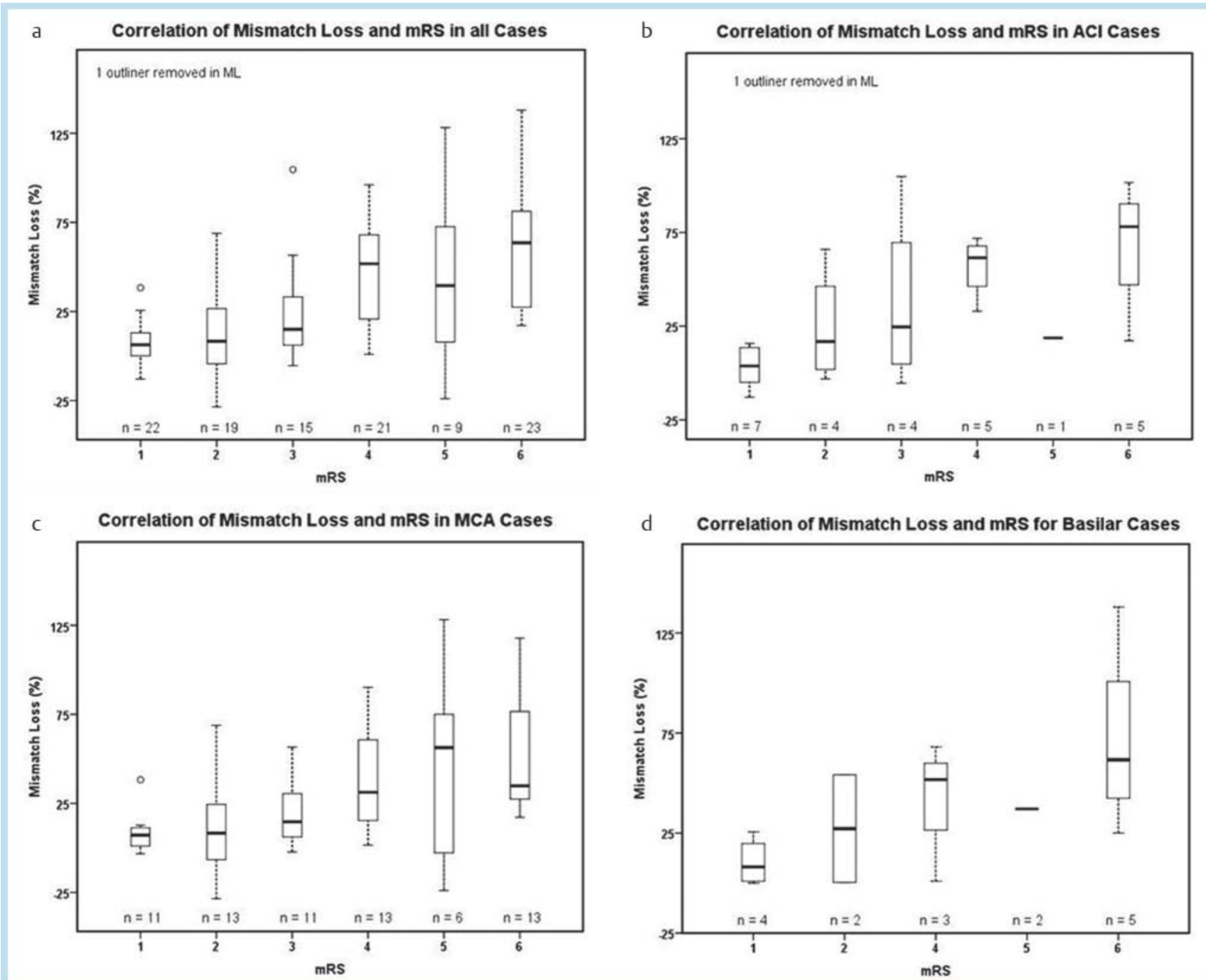

Fig. 2 a shows the boxplot analysis of the correlation between \%ML and $\mathrm{mRS}$ for all cases. $\mathbf{b}$ shows the boxplot analysis of the correlation between \%ML and mRS for ICA. c shows the boxplot analysis of the correlation between \%ML and mRS for MCA. $\mathbf{d}$ shows the boxplot analysis of the correlation between \%ML and mRS for BA.

Abb. 2 a zeigt die Boxplot Analyse der Korrelation zwischen \%ML und mRS für alle Daten. b zeigt die Boxplot Analyse der Korrelation zwischen \%ML und mRS für das ICA-Stromgebiet. c zeigt die Boxplot Analyse der Korrelation zwischen \%ML und mRS für das MCA-Stromgebiet. d zeigt die Boxplot Analyse der Korrelation zwischen \%ML und mRS für das BA-Stromgebiet.

rates $16.5 \%(16 / 103)$ were detected than in pRESET clot retriever cases $8.3 \%(4 / 48)$.

The median \%ML in our data was $19 \%$. Values ranging from $0-$ $20 \%$ were defined as a surrogate parameter for successful recanalization in time (correlated to individual collaterals).

The 3-month mRS revealed a good "CO" (0-2 mRS) in 49/136 cases (36\%), a fair outcome (3-4 mRS) in $42 / 136$ cases (30.9\%) and a poor outcome ( $5-6 \mathrm{mRS}$ ) in $45 / 136$ cases ( $33.1 \%)$.

Patients in mRS subgroup $0-2$ showed a \%ML of $0-20 \%$ in $69.4 \%$ of cases. The total median \%ML of these cases in subgroup 0-2 was $6 \%$. In contrast, the median \%ML of patients in subgroup 6 was $62 \%$.

\section{Correlations of parameters (Please use 0 Table 1}

for an overview of all correlations)

We found a statistically significant, positive correlation between \%ML and mRS (Spearman's correlation coefficient (c) $=0.48$, (Kruskal-Wallis (KW) test, p-value (p) <0.001) ( $\bullet$ Fig. 2a). Considering each vascular territory separately, we found a match between \%ML and mRS of $0.46(p=0.015)$ for ICA ( $\bullet$ Fig. $2 b$ ), $0.49(p<0.001)$ for MCA ( $\odot$ Fig. $2 c)$ and $0.47(p=0.06)$ for BA (० Fig. 2d).

There was an overall significant negative correlation for TICI and mRS ( $c=-0.35, p=<0.001)$ ( $\bullet$ Fig. 3), while for ICA the correlation was $-0.42(p=0.016)$, for MCA $-0.52(p<0.001)$, and for BA -0.02 $(\mathrm{p}=0.930)$.

There was only a weak correlation between the infarct core and $\mathrm{mRS}$ of $0.14(\mathrm{p}=0.039)$ ( $\bullet$ Fig. 4). There were highly significant correlations for ICA of $0.44(p=0.02)$, and for BA of $0.47(p=0.048)$, but none for MCA ( $c=0.06, p=0.582)$.

There were significant correlations between the final infarct volume and mRS: All cases included ( $c=0.52, p<0.001)$ ( $\bullet$ Fig. 5), ICA $(c=0.62, p<0.001), \operatorname{MCA}(c=0.48, p<0.001)$ and BA $(c=0.78$, $\mathrm{p}<0.001)$.

A positive correlation was detected between mRS and age $(c=0.37, p<0.001)$ ( $\bullet$ Fig. 6$)$. For ICA alone the correlation was $0.43(p=0.013)$, for MCA it was $0.33(p=0.03)$ and for BA it was $0.30(\mathrm{p}=0.136)$. 


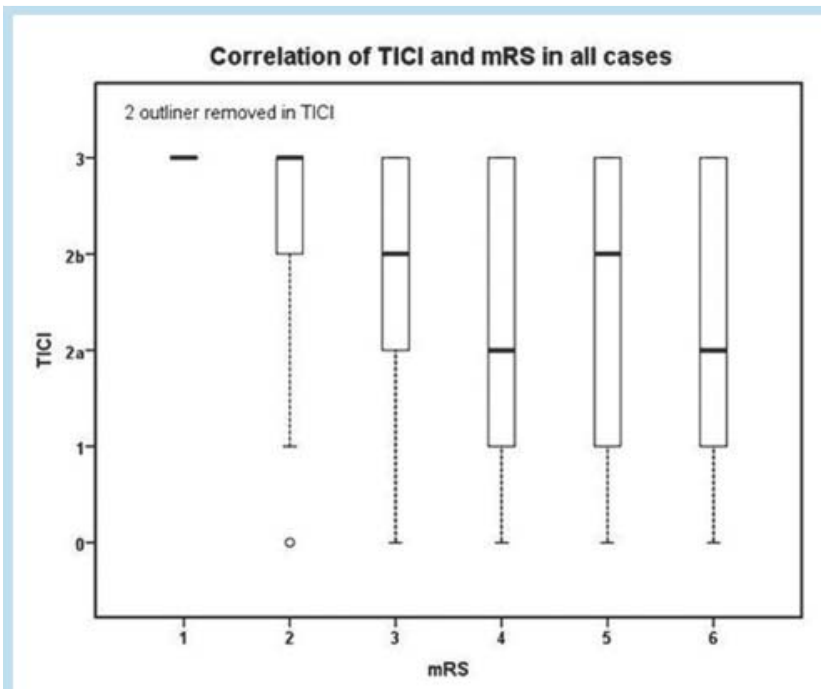

Fig. 3 shows the boxplot analysis of the correlation for $\mathrm{TICl}$ and $\mathrm{mRS}$ in all vascular territories. Better recanalization grades are associated with a better clinical outcome (lower average mRS scales).

Abb. 3 zeigt die Boxplot Analyse der Korrelation zwischen TICl und mRS für alle Stromgebiete. Bessere Rekanalisationsgrade sind mit einem besseren klinischen Outcome assoziiert (niedrigere mRS-Subklassen).

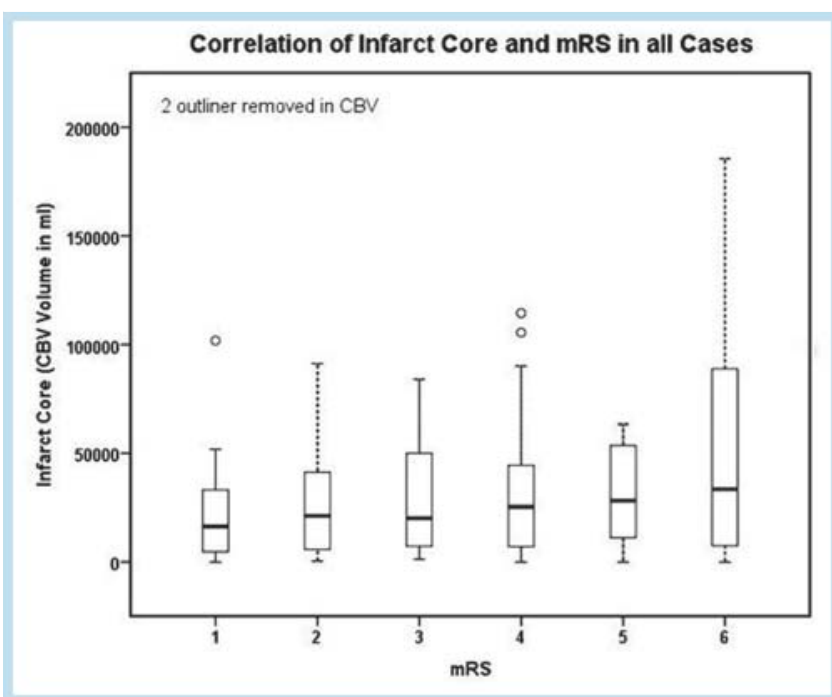

Fig. 4 In the boxplot analysis the correlation of infarct core and mRS is shown.

Abb.4 In der Boxplot Analyse wird die Korrelation zwischen Infarktkern und mRS gezeigt.

No correlation was found for time to recanalization and mRS ( $c=0.07, p=0.451$ ), for post-interventional bleeding and $\mathrm{mRS}$ $(c=0.02, p=0.819)$ not for collateralization grade and $\mathrm{mRS}$ $(c=0.02, p=0.817)$.

\section{Nominal regression model}

The nominal regression model with the independent variables $\% \mathrm{ML}$, age and bleeding, calculated on the basis of 107 cases, predicted the correct class of "CO" (mRS) for $49.5 \%$ of cases († Table 2 ). In a single nominal regression model for $\mathrm{mRS}$, \%ML alone predicted

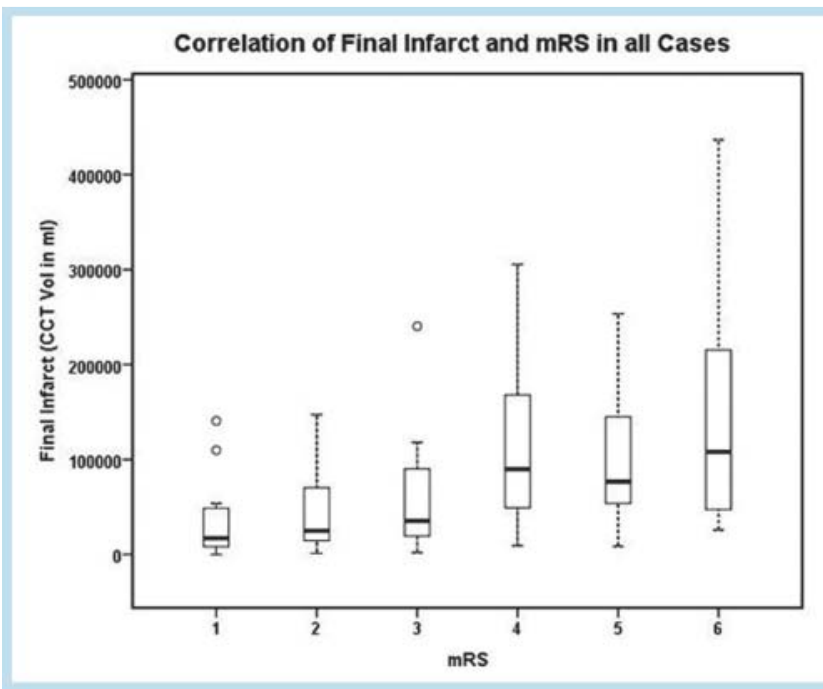

Fig. 5 shows the boxplot analysis of the correlation for final infarct volume and $\mathrm{mRS}$.

Abb.5 zeigt die Boxplot Analyse der Korrelation zwischen finalem Infarktvolumen und mRS.

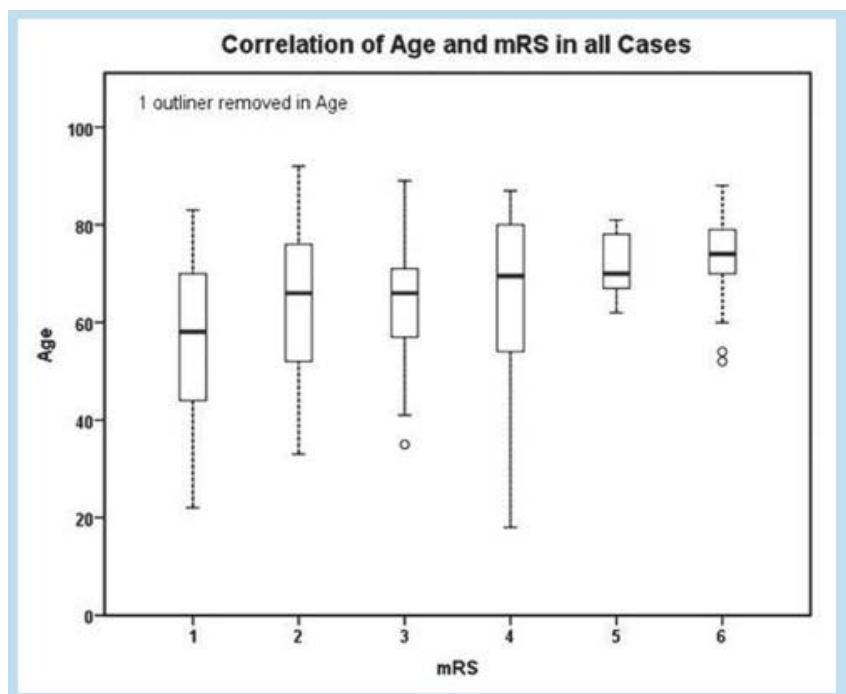

Fig. 6 In the boxplot analysis the correlation between age and modified Rankin Scales (mRS) is shown. Older patients present with higher mRS subclasses.

Abb. 6 Die Boxplot Analyse zeigt die Korrelation zwischen Alter und mRS. Ältere Patienten weisen höhere mRS-Subklassen auf.

$38.5 \%$ of these cases correctly ( $\bullet$ Table 2 ). The single nominal regression model for mRS was also constructed separately for the three arterial territories. On the basis of 26 (ICA), 67 (MCA) and 16 (basilar artery) occlusions, a prognostic value of \%ML was found for mRS of 53.8\% (ICA), 31.3\% (MCA) and 56.2\% (basilar artery), respectively ( $\bullet$ Table 3$)$. 
Table 3 Predictive classification of $\mathrm{mRS}(0,1,2,3,4,5,6)$ by \%ML according to nominal regression models, each for ICA, MCA and BA. Table 3 shows the classification of mRS calculated with nominal regression models based on \% $\mathrm{ML}$ as only independent variable for each vascular territory separately. The percentage predictability of good outcome (mRS 1 ) and poor outcome (mRS 6) is remarkably strong for ICA and basilary artery occlusions regarding the factor \%ML.

Tab. 3 Vorhersage der Klassifizierung von mRS $(0,1,2$, 3, 4, 5, 6) für ICA, MCA und BA durch \%ML anhand einer nominalen Regressionsanalyse. Tab. 3 zeigt die errechnete Klassifikation des mRS durch die nominale

Regressionsanalyse, basierend auf \%ML als alleinige unabhängige Variable. Diese Analyse wurde für jedes Gefäßareal separat durchgeführt. Die prozentuale Vorhersagbarkeit der guten Outcomes (mRS 1) und schlechten Outcomes (mRS 6) in Bezug auf den Parameter \%ML ist bemerkenswert hoch für ICA- und Basilarisverschlüsse.

\begin{tabular}{|llcl|}
\hline $\begin{array}{l}\text { classification } \\
\text { (mRS) }\end{array}$ & $\begin{array}{l}\text { \%ML (ICA) } \\
\text { correctly } \\
\text { predicted (\%) }\end{array}$ & $\begin{array}{l}\text { \%ML (MCA) } \\
\text { correctly } \\
\text { predicted (\%) }\end{array}$ & $\begin{array}{l}\text { \%ML (BA) } \\
\text { correctly } \\
\text { predicted (\%) }\end{array}$ \\
\hline 1 & $7 / 7(100)$ & $0 / 11(0)$ & $4 / 4(100)$ \\
\hline 2 & $1 / 4(25)$ & $10 / 13(76.9)$ & $0 / 2(0)$ \\
\hline 3 & $1 / 4(25)$ & $0 / 11(0)$ & $0 / 0(-)$ \\
\hline 4 & $2 / 5(40)$ & $4 / 13(30.8)$ & $0 / 3(0)$ \\
\hline 5 & $0 / 1(0)$ & $0 / 6(0)$ & $1 / 2(50)$ \\
\hline 6 & $3 / 5(60)$ & $7 / 13(53.8)$ & $4 / 5(80)$ \\
\hline total & $14 / 26(53.8)$ & $21 / 67(31.3)$ & $9 / 16(56.2)$ \\
\hline
\end{tabular}

\section{Discussion}

$\nabla$

The presented positive correlation between tissue outcome ("TO") as defined by \%ML or infarct growth and clinical outcome ("CO") as defined by mRS indicates once again that a successful recanalization procedure with ongoing reperfusion is directly related to a better "CO". \%ML and the final infarct volume show a stronger correlation than TICI score, reflecting that "TO" in stroke should be based on two principles: perfusion imaging by CT or MRI as initial workup and post-stroke volume imaging of infarct size as a control of stroke therapy, addressing the fact that not only recanalization but also successful reperfusion are relevant factors for good "CO" and should be the final goal of interventional stroke therapy. Moreover, in the nominal regression model, "TO" revealed the strongest impact on "CO", as compared to other variables like age and lysis-related cerebral hemorrhage.

Collateral status as measured in our study failed to be a significant factor and was not included in the nominal regression model. This may be due to the fact that CTA and not CT perfusion was used to assess collaterals and that the factor of time invariance was not recorded using CTA instead of 4D-CTA on the basis of CT perfusion data or angiography as performed elsewhere [6]. The recanalization grade (TICI) showed a significant negative correlation to the "CO" (mRS). While no correlation was found between TICI and "CO" in the posterior circulation, significant matches were found for anterior cerebral infarctions, showing comparable values for ICA and MCA occlusions. The same fact was seen with the "TO" (\%ML) and mRS, where this correlation was not significant for the basilar region, but highly significant for the anterior circulation.

In contradiction to these findings, the volume of final infarct and "CO" (mRS) shows a significant correlation for both the anterior and posterior circulation. Furthermore, the regression analysis revealed a strong influence of \%ML on the mRS in patients having suffered from basilar artery occlusion.
Thus assessing posterior circulation occlusions with CT perfusion for predicting clinical outcome is more doubtful than assessing anterior circulation occlusions in the recent setting of stroke CT, because the higher density or concentration of clinically relevant structures in the brain stem may result in larger effects of rather small lesions than in the anterior circulation.

Most publications used the recanalization on the arterial level versus "CO" as the endpoint and did not calculate "TO" to estimate the effect of recanalization on the brain's parenchyma [7]. In our study we found a prognostic value of \%ML in terms of "CO", showing that recanalization cannot automatically mean complete reperfusion and scientific workup should be reconsidered [24].

Together with age and the existence of bleeding, \%ML could explain the variability in mRS in about $50 \%$. Especially the results in patients who scored mRS 1 and 6 can be predicted by \%ML with high reliability.

After pre-selection of the patients by the above multimodal stroke imaging and by excluding patients without penumbra, we can predict that a mean \%ML of $19 \%$ or less is sufficient to result in a smaller infarct and a better clinical recovery.

Our study showed no correlation between time to recanalization and "CO" (mRS). This matches the findings of other studies also describing a missing relationship between time to recanalization and "CO" but contradicts the data of large controlled studies for $i$. v. lysis therapy $[2,25]$. The missing correlation between time to recanalization and "CO" in this study can be due to a selection effect of patients with mismatch for recanalization therapy, detected by perfusion CT imaging, and followed by fast recanalization. In extensive trials of $i . v$. lysis, time to recanalization does influence the "TO" as expected by the existing data, where native CCT was the basis for treatment decision. The length of intervention and existence of postinterventional hemorrhage vary in our datasets depending on the use of different devices for recanalization. Our results indicate less sufficient performance of penumbra devices. Both the length of intervention and the rate of postoperative hemorrhage are worse than that of the pRESET clot retriever.

In a multimodal stroke CT setting, radiation exposure has to be considered to be as low as reasonably achievable. The grade of temporal resolution defines the number of scan repetitions and should be tested in the clinical condition. Temporal resolutions up to two seconds can still be diagnostic [17]. We selected $1.5 \mathrm{~s}$ as the ideal compromise between acceptable temporal resolution and radiation exposure. Replacing the CTA by a CTA being reconstructed from CT perfusion data (VPCTA) should be the next step to reduce radiation exposure in a multimodal CT stroke setting as the diagnostic value of VPCTA is comparable to the standard CTA technique.

\section{Conclusion \\ $\nabla$}

Our results indicate that more than a successful mechanical recanalization, a low \%ML or low final infarct volume as a surrogate parameter for successful reperfusion, representing a good "TO", is highly relevant for a good "CO" after interventional stroke therapy. Further efforts in developing DSA tools are needed to assess tissue parameters for reperfusion under interventional conditions.

Apart from the final infarct volume, post-interventional \%ML based on the penumbra concept is the most exact parameter for 
"TO". \%ML of $20 \%$ could be defined as the border between favorable und unfavorable outcome in our study. This should be the basis of scientific stroke investigation for the anterior circulation, irrespective of the presence of ICA or MCA occlusion, but not for basilar artery occlusion to date.

Age, presence of bleeding and \%ML together can statistically predict "CO" in $41.7-72.7 \%$ of our cases in the group mRS 0-2, where \%ML itself can explain the variability in $\mathrm{mRS}$ in $38.5 \%$ of our cases. Especially the good (mRS 1) and poor (mRS 6) "COs" are predicted by \%ML with high precision.

\section{Clinical relevance}

\% $\%$ ML as well as the final infarct volume can make a direct point about the effect of successful mechanical recanalization and it is crucial for the subsequent clinical condition.

- The clinical outcomes are predicted by \%ML with high precision, reflecting the need for escalation therapy including interventional reopening of parent vessel occlusions.

- Small tissue loss, as evaluated by perfusion CT in \%ML and final infarct volume, indicated better "CO" after mechanical recanalization than $\mathrm{TICI}$ score, showing that not recanalization itself, but reperfusion should be regarded as a surrogate parameter for successful stroke therapy.

\section{Affiliations}

Institute for Clinical Radiology, University Hospital Muenster, Germany

2 Department of Neuroradiology, University Hospital Schleswig-Holstein, Lübeck, Germany

3 Institute of Biostatistics and Clinical Research, University of Muenster, Germany

${ }^{4}$ Department of Neurology, University Hospital Muenster, Germany

5 Radiology/Neuroradiology, Asklepios-Clinic North, Hamburg, Germany

\section{References}

1 Sarti C, Rastenyte D, Cepaitis $Z$ et al. International trends in mortality from stroke, 1968 to 1994. Stroke 2000; 31: 1588-1601

2 Costalat V, Lobotesis $K$, Machi $P$ et al. Prognostic factors related to clinical outcome following thrombectomy in ischemic stroke (RECOST study). 50 patients prospective study. Eur J Radiol 2012; 81: 40754082

3 Hallevi $H$, Barreto $A D$, Liebeskind DS et al. Identifying patients at high risk for poor outcome after intra-arterial therapy for acute ischemic stroke. Stroke 2009; 40: 1780-1785

4 Kidwell CS, Jahan R, Gornbein J et al. A trial of imaging selection and endovascular treatment for ischemic stroke. N Engl J Med 2013; 368: 914-923

5 Lansberg MG, Straka M, Kemp S et al. MRI profile and response to endovascular reperfusion after stroke (DEFUSE 2): a prospective cohort study. Lancet Neurol 2012; 11: 860-867

6 Liebeskind DS, Tomsick TA, Foster LD et al. Collaterals at angiography and outcomes in the Interventional Management of Stroke (IMS) III trial. Stroke 2014; 45: 759-764

7 Hesselmann V, Niederstadt T, Dziewas R et al. Reperfusion by combined thrombolysis and mechanical thrombectomy in acute stroke: effect of collateralization, mismatch, and time to and grade of recanalization on clinical and tissue outcome. AJNR American journal of neuroradiology 2012; 33: 336-342

8 Rai AT, Carpenter JS, Raghuram K et al. Endovascular therapy yields significantly superior outcomes for large vessel occlusions compared with intravenous thrombolysis: is it time to randomize? Journal of neurointerventional surgery 2013; $5: 430$-434

9 Broderick JP, Palesch YY, Demchuk AM et al. Endovascular therapy after intravenous t-PA versus t-PA alone for stroke. N Engl J Med 2013; 368: 893-903

10 Chimowitz MI. Endovascular treatment for acute ischemic stroke-still unproven. N Engl J Med 2013; 368: $952-955$

11 Ciccone A, Valvassori L, Nichelatti $M$ et al. Endovascular treatment for acute ischemic stroke. N Engl J Med 2013; 368: 904-913

12 Cohen JE, Rabinstein AA, Ramirez-de-Noriega $F$ et al. Excellent rates of recanalization and good functional outcome after stent-based thrombectomy for acute middle cerebral artery occlusion. Is it time for a paradigm shift? J Clin Neurosci 2013; 20: 1219-1223

13 Grunwald IQ Walter S, Papanagiotou P et al. Revascularization in acute ischaemic stroke using the penumbra system: the first single center experience. Eur J Neurol 2009; 16: 1210-1216

14 Adams HPJr, del Zoppo G, Alberts MJ et al. Guidelines for the early management of adults with ischemic stroke: a guideline from the American Heart Association/American Stroke Association Stroke Council, Clinical Cardiology Council, Cardiovascular Radiology and Intervention Council, and the Atherosclerotic Peripheral Vascular Disease and Quality of Care Outcomes in Research Interdisciplinary Working Groups: the American Academy of Neurology affirms the value of this guideline as an educational tool for neurologists. Stroke 2007; 38: 1655-1711

15 Wintermark M. Brain perfusion-CT in acute stroke patients. Eur Radiol 2005; 15: D28 - D31

16 Nael K, Meshksar A, Liebeskind DS et al. Quantitative analysis of hypoperfusion in acute stroke: arterial spin labeling versus dynamic susceptibility contrast. Stroke 2013; 44: 3090-3096

17 Abels B, Klotz E, Tomandl BF et al. CT perfusion in acute ischemic stroke: a comparison of 2-second and 1-second temporal resolution. AJNR American journal of neuroradiology 2011; 32: 1632-1639

18 Wintermark $M$, Flanders AE, Velthuis B et al. Perfusion-CT assessment of infarct core and penumbra: receiver operating characteristic curve analysis in 130 patients suspected of acute hemispheric stroke. Stroke 2006; 37: 979-985

19 Ay H, Arsava EM, Koroshetz WJ et al. Middle cerebral artery infarcts encompassing the insula are more prone to growth. Stroke 2008; 39: $373-378$

20 Knauth M, von Kummer R, Jansen $O$ et al. Potential of CT angiography in acute ischemic stroke. AJNR American journal of neuroradiology 1997; 18: $1001-1010$

21 Hesselmann V, Dziewas R, Kemmling $M$ et al. Darstellung der Kollateralisation zerebraler Gefäßverschlüsse durch zeitlich aufgelöste CTA zur Einschätzung der Lyse- und Rekanalisationsfähigkeit. Jahrestagung der deutschen Gesellschaft 7-9 Oktober 2009

22 Tan IY, Demchuk AM, Hopyan J et al. CT angiography clot burden score and collateral score: correlation with clinical and radiologic outcomes in acute middle cerebral artery infarct. AJNR American journal of neuroradiology 2009; 30: 525-531

23 Tomsick T. TIMI, TIBI, TICI: I came, I saw, I got confused. AJNR American journal of neuroradiology 2007; 28: $382-384$

24 Liebeskind DS, Sanossian N. How well do blood flow imaging and collaterals on angiography predict brain at risk? Neurology 2012; 79: S105S109

25 Lees KR, Bluhmki E, von Kummer R et al. Time to treatment with intravenous alteplase and outcome in stroke: an updated pooled analysis of ECASS, ATLANTIS, NINDS, and EPITHET trials. Lancet 2010; 375: $1695-1703$ 